\title{
Group identity and peer relations: A longitudinal study of group identity, perceived peer acceptance, and friendships amongst ethnic minority English children
}

\author{
Adam Rutland ${ }^{*}$, Lindsey Cameron', Philipp Jugert ${ }^{2}$, \\ Dennis Nigbur ${ }^{3}$, Rupert Brown ${ }^{4}$, Charles Watters', \\ Rosa Hossain', Anick Landau ${ }^{4}$ and Dominique Le Touze ${ }^{4}$ \\ 'University of Kent, UK \\ ${ }^{2}$ Friedrich Schiller University Jena, Germany \\ ${ }^{3}$ Canterbury Christ Church University, UK \\ ${ }^{4}$ University of Sussex, UK
}

\begin{abstract}
This research examined whether peer relationships amongst ethnic minority status children reflect the social groups to which children belong and the degree to which they identify with these groups. A longitudinal study was conducted to investigate the influence of group identities (i.e., ethnic and national) on children's perceived peer acceptance and preference for same-ethnic friendships. Measures of ethnic and English identification, perceived peer acceptance, and friendship choice were administered to 207 south-Asian English children, aged between 5 and II, at two time points 6 months apart. In line with predictions, longitudinal analysis showed that bicultural identification (i.e., higher ethnic and English identity) was related to higher perceived peer acceptance and less preference for same-ethnic friendships. Importantly, as hypothesized, this finding was limited to the older children with more advanced social-cognitive abilities. The results suggest that older children who adopted a bicultural identity were able to strategically 'flag' their multiple group identities, within their multicultural peer groups, to obtain acceptance amongst the maximum number of peers and show less preference for same-ethnic friendships. This study extends previous peer relations research, which has typically focused on individual social deficits or classroom norms, by showing that group identities influence peer relationships amongst ethnic minority status children.
\end{abstract}

Peer relations are a ubiquitous aspect of social life from early childhood, and in forming peer relationships children regularly make decisions about social exclusion and inclusion (Killen \& Rutland, 2011). Social exclusion from peer groups has been associated in

\footnotetext{
* Correspondence should be addressed to Adam Rutland, School of Psychology, Child Development Unit, University of Kent, Canterbury CT2 7NP, UK (e-mail: a.rutland@kent.ac.uk).
} 
later life with depression, psychological maladjustment, poor academic achievement, violence, and school dropout (Boivin, Hymel, \& Bukowski, 1995; Hymel, Vaillancourt, McDougall, \& Renshaw, 2002). To date, most studies of peer relations have focused on how individual social deficits lead children to reject peers (e.g., aggressive and lack of sensitivity to social cues) and be rejected by their peers (e.g., fearful, socially anxious, and shy). The majority of existing research has also tended to focus on ethnic majority status children in relatively ethnically homogenous settings (e.g., Hay, Payne, \& Chadwick, 2004). This paper describes a longitudinal study that takes an original approach to peer relations by examining the role of group identities (i.e., ethnic and national identities) in the formation of peer relationships, in particular, perceived peer acceptance and friendships amongst ethnic minority status English children living in culturally heterogeneous communities.

Social exclusion within groups occurs for many reasons (see Abrams, Hogg, \& Marques, 2005; Killen \& Rutland, 2011). Typically, developmental psychology research has focused on the intrapersonal (e.g., high aggression, pre-disposition to an emotional temperament, poor ability to read communication cues from peers) basis of social exclusion amongst peers (see Rubin, Bukowski, \& Parker, 2006). This research focuses primarily on individual dispositions and pays little attention to the interaction between peers within a group. Recent developmental research has not relied solely on a developmental psychopathology model for understanding patterns of exclusion and peer rejection (Chang, 2004; Juvonen, Gross, Williams, Forgas, \& von Hippel, 2005). For example, Chang (2004) showed that social norms in classrooms about prosocial-leadership, aggression, and social withdrawal influenced Chinese children's peer relations. In classrooms where a high level of social withdrawal was perceived as normal, children who showed this behaviour were more accepted by their peers.

This research shows the importance of the individual-group relationship in terms of the classroom when considering peer relations. However, research on children's group identities, intra-group and inter-group relations (see Abrams \& Rutland, 2008; Bennett \& Sani, 2004; Nesdale, 2008; Rutland, Killen, \& Abrams, 2010), suggests another notion of the 'group' may influence children's peer relationships. This is children's sense of group identity or social self (e.g., identification with their gender, ethnic, racial, or national group). For example, a girl may be rejected from an all-boy group on the basis of being a girl, not just because of her perceived personality traits (e.g., shyness).

We contend that peer acceptance or rejection should also reflect the social groups to which children belong and the degree to which they identify with each group. This should be especially true for the ethnic minority status children living in multicultural communities examined within this study. Ethnic minority status children are able to identify with both their ethnic group (e.g., south Asian or Indian), and additionally, with their national group (i.e., English) that also includes ethnic majority status children (i.e., white English). They have to construct their sense of social self as a member of more than one cultural group and navigate their multicultural environment.

Research with children has shown that identity activation influences children's perceptions and behaviour (e.g., Ambady, Shih, Kim, \& Pittinsky, 2001; Sani \& Bennett, 2001; Verkuyten \& Pouliasi, 2002; Wang, Shao, \& Li, 2010). For example, Verkuyten \& Pouliasi (2002) demonstrated that older 9- to 12-year-old bicultural Greek children living in the Netherlands engaged in cultural frame switching (i.e., a process by which biculturals have access to and apply two different cultural meaning systems in response to cultural cues). They found that activating Greek identity salience, compared to Dutch identity salience, amongst these bicultural children leads to more external attributions, 
stronger connectedness with friends, and more positive evaluations of the social rather than the personal self. This study suggests that 9- to 12-year-old bicultural children are able to cultural frame switch between their multiple group identities, and this has implications for their perceptions and behaviour. This ability arguably advantages bicultural children compared to monocultural children in their peer relationships. It means they can strategically 'flag' or perform their multiple identities to both their ethnic minority and ethnic majority status peer group, for gaining acceptance amongst the maximum number of peers within their multicultural environment.

The advantage bicultural individuals have when seeking recognition within their multicultural peer groups, in part, might explain why research suggests biculturalism has many positive psychological outcomes (Benet-Martinez \& Haritatos, 2005; Berry, Phinney, Sam, \& Vedder, 2006; LaFromboise, Coleman, \& Gerton, 1993). For example, research shows that bicultural individuals show better social-emotional adaptation (i.e., higher self-esteem, fewer mental health problems) than their peers with more monocultural group identities (LaFromboise et al., 1993; Phinney, Cantu, \& Kurtz, 1997). Recent research suggests a link between bicultural identification amongst parents and positive child functioning (Calzada, Brotman, Huang, Bat-Chava, \& Kingston, 2009). This study found that bicultural parents (i.e., those with high ethnic and US American identity) had pre-school children with lower levels of internalizing problems (e.g., anxiety, depression, and somatization) and higher levels of adaptive behaviour and social skills within the peer group (e.g., good communication skills and high peer acceptance) relative to parents who did not have a bicultural identity. The implication of this research is that bicultural parents are more likely to raise children who also develop a bicultural identity, which acts as a protective factor to counteract any risks associated with child rearing in a high-risk environment, and results in better social competence and approval within the peer group (Knight, Virdin, \& Roosa, 1994).

The present study will extend previous research by examining bicultural identity in 5- to 11-year-old children, investigating whether this bicultural identity (i.e., high ethnic and English identity) is longitudinally related to greater perceived peer acceptance. Given the research described above, we expect children with a bicultural identity compared to those with a more monocultural identity will be better able to gain acceptance within both their ethnic minority and ethnic majority status peer groups. Consequently, they should report more perceived peer acceptance and less social exclusion from their peer groups.

We will measure bicultural identity in children by drawing on an interactional framework for understanding group identity amongst ethnic minority children and adolescents (Phinney, Horenezyk, Liebkind, \& Vedder, 2001). This model does not assume a simple continuum from bicultural to monocultural identification. Instead, it contends that individuals experience independent feelings about their (or their family's) culture of origin (i.e., ethnic group) and a second culture (i.e., national group). Therefore, our measure of children's bicultural identity will be based upon their independent identification with their ethnic group (e.g., Indian, Sikh) and national group (i.e., England).

In our research, we will also investigate the influence of bicultural identity amongst ethnic minority status children on their preference for same-ethnic friendships. Research on children indicates that less preference for same-ethnic friendships (i.e., more intergroup friendship) is related to more positive attitudes towards other ethnic groups (see Killen \& Rutland, 2011; Tropp \& Prenovost, 2008). Recent research has also found the reverse relationship amongst adolescents (Binder et al., 2009) and children 
(Jugert, Noack, \& Rutland, 2011), with positive inter-ethnic attitudes predicting less preference for same-ethnic friendships. The study by Jugert et al., also suggests that by emphasizing shared characteristics (i.e., classroom identification) ethnic minority children's preference for same-ethnic friendships can be overcome. They found over time that classroom identification, which was shared by both ethnic minority and majority status children, increasingly reduced preference for same-ethnic friendships amongst Turkish children living in Germany. Other developmental research has also demonstrated that identification with multiple groups, including a shared identity (e.g., nation), leads to more positive attitudes towards others from different groups (e.g., Cameron, Rutland, Brown, \& Douch, 2006; Pfeifer et al., 2007; Phinney, Jacoby, \& Silva, 2007).

These findings are in line with the 'common ingroup identity' model of inter-group contact, which has shown that contact between different social groups is most effective in promoting positive inter-group attitudes when both the ingroup and outgroup are redefined as one superordinate group (e.g., a common national identity). Sharing a common identity is effective because it increases perception of 'us' rather than 'we' and 'them' (Gaertner et al., 2008). Research on inter-group contact also suggests that a common identity (e.g., American), combined with a subgroup identity (e.g., Latino), known as a 'dual identity' approach (see Brown \& Hewstone, 2005; Cameron et al., 2006) is especially effective amongst children in promoting positive inter-group attitudes. This emphasis on a 'dual identity' has much similarity with a bicultural identity. Together the research described above suggests that bicultural identification (i.e., high ethnic and national identity) amongst ethnic minority status children should generate positive inter-group attitudes, and such attitudes should in turn be related to less preference for same-ethnic friendships (i.e., more inter-group contact).

We also anticipate that the effect of bicultural identification on perceived peer acceptance and preference for same-ethnic friendships will depend on the age of the child. Our sample includes children who range in age from 5 to 11 years. There are important social-cognitive skills that develop across this age range that should impact children's ability to strategically 'flag' or perform multiple identities and switch their cultural frame of reference. Previous research has only showed that older children (i.e., above 8-9 years of age) adopt a bicultural identity and strategically present their cultural self-depending on which element of their bicultural identity is most salient (Verkuyten \& Pouliasi, 2002; Wang et al., 2010). We are not aware of research showing evidence of such self-presentation involving multiple identities amongst children less than 8-9 years of age, which is not surprising since younger children are known to lack two relevant social-cognitive abilities.

Firstly, a key to children adopting a bicultural identity effectively may be their ability to simultaneously consider multiple social categories or group memberships (i.e., ethnic and national). This ability to consider multiple social categories simultaneously is known to develop in middle childhood, but is thought to emerge from only around 7 or 8 years of age (Barenboim, 1981; Bigler, 1995; Livesley \& Bromley, 1973). Therefore, only after this age are children likely to simultaneously consider and identify strongly with multiple social categories and successfully adopt a bicultural identity. Secondly, research indicates that only beyond 7-8 years of age do children begin to show advanced social perspective taking, which means they are able to perceive what various individuals think and feel, demonstrating sensitivity to the multiple links between thoughts, feelings, and behaviour within social interactions (Abrams, Rutland, Pelletier, \& Ferrell, 2009; Banerjee, 2000; Baron-Cohen, O'Riordan, Stone, Jones, \& Plaisted, 1999). This type of social perspective 
taking or 'Theory of Social Mind' (Abrams et al., 2009; FitzRoy \& Rutland, 2010) and multiple classification skill should be evident amongst the older children within the present study. These abilities we predict will allow older children to effectively adopt a bicultural identity and strategically perform their different group commitments to all types of peers within their multicultural environment. The result should be higher levels of peer acceptance, and less preference for same-ethnic friendships amongst older ethnic minority children with a bicultural identity.

The current research adopts a longitudinal design to examine the antecedents of peer relations amongst ethnic minority status children living in multicultural settings. This longitudinal study is an advance on previous cross-sectional studies of peer relations since it allows for more confidence in drawing inferences about causal relationships. The present study specifically complements and extends previous peer relations research by focusing on whether bicultural identification longitudinally affects children's perceived peer acceptance and preference for same-ethnic friendships. We anticipate that as children increasingly adopt a bicultural identity (i.e., high ethnic and national identity), they will report more perceived acceptance within their peer group. This should be due to their ability to 'flag' or perform their multiple identities for gaining maximum acceptance amongst both ethnic minority and majority status groups. In addition, we expect that with increasing bicultural identification ethnic minority status children will show more positive inter-group attitudes, which will be reflected in less preference for friendships with peers from their ethnic group. Finally, we think these longitudinal effects of bicultural identity on perceived peer acceptance and friendship amongst ethnic minority status children will only be shown by older children. We contend that this will be due to their more advance social-cognitive abilities, which allow them to simultaneously consider multiple identities and take the social perspective of others when strategically presenting their different group identities within multicultural settings.

\section{Method}

\section{Participants}

Participants consisted of 207 (105 boys, 102 girls) south-Asian English ethnic minority status children aged between 5 and 11 years $(M=7$ years and 11 months, $S D=$ 17.99 months). The children were recruited from 19 schools in ethnically heterogeneous, semi-urban, and lower-middle socioeconomic status (SES) areas outside a major metropolitan city. The ethnic breakdown of these English children was as follows: $78.7 \%$ Indian, 8.2\% Pakistani, 4.8\% Sri Lankan, 2.4\% Bengali, 1.4\% Nepalese, and 0.5\% Tamil. The ethnic composition of these schools varied from $2 \%$ to $62 \%$ ethnic minority status children (median 20\%), and classroom compositions were similar to these school figures.

\section{Measures}

Perceived peer acceptance

This measure was based on the Cassidy and Asher's Loneliness and School Dissatisfaction Questionnaire (Cassidy \& Asher, 1992). Research has shown that peer rejection is significantly and positively related to loneliness and school dissatisfaction measured using the Cassidy and Asher Questionnaire (e.g., Berlin, Cassidy, \& Belsky, 1995; Cassidy \& Asher, 1992; Coplan, Closson, \& Arbeau, 2007; Woods, Done, \& Kalsi, 2009). Therefore, this measure was used as an indicator of children's perceived acceptance. We created 
Table I. Items included in measure of perceived peer acceptance (adopted from Cassidy \& Asher, 1992)

I. Do you have other kids to talk to at school?

2. Is it hard for you to make friends at school? (reverse scored)

3. Do you have lots of friends at school?

4. Do you feel alone at school? (reverse scored)

5. Is it hard to get kids in school to like you? (reverse scored)

6. Do you have kids to play with at school?

7. Do you get along with other kids at school?

8. Do you feel left out of things at school?

9. Are you lonely at school?

10. Do the kids at school like you?

a shortened version of the original Loneliness and School Dissatisfaction Questionnaire using 10 of their original 25 items (see Table 1 for items). The 10 items selected from the original measure were chosen as they had the highest loadings on the single factor found by Cassidy and Asher (1992). Children were, therefore, presented with 10 questions relating to their feelings of loneliness at school, to which they responded on a 4-point scale $(1=$ not at all, $2=$ a little bit, $3=$ quite, and $4=$ very much). These responses were illustrated pictorially with pictures of a balloon that increased in size from 'not at all' to 'very much'. Analyses showed a satisfactory internal reliability for these 10 items (Cronbach's alpha $=.76$ ), therefore, composite mean scores were created. The resulting scores range from 1 to 4 with lower scores indicating lower levels of perceived peer acceptance, and higher scores indicating higher levels of perceived peer acceptance.

\section{Ethnic and English identity}

We wanted to measure the strength of children's identification with their ethnic minority status group and national group. Firstly, it was important to ascertain the ethnic minority status groups with which the children identified. This was necessary because it allowed us to measure children's strength of identification with their ethnic minority group without imposing groups or categories on them. In order to do this, children were presented with a list of group memberships to which they might identify. These group memberships included: (1) ethnic/national minority status groups ('Sri Lankan', 'Bengali', 'Hindu', 'Nepalese', 'Indian', 'Muslim', 'Pakistani', 'Asian', and 'Sikh'); (2) ethnic/national majority status groups ('white', 'English', 'British', and 'Christian') as well as some fillers ('girl' and 'boy') and an 'other' category. Children were asked to identify the words that they would use to describe themselves. Seventy-five percent of the children selected 'Indian' and all of these children also identified themselves as belonging to a religious group (especially Sikh and Hindu). Twenty-four percent of the children chose 'Asian' with all of these children also identifying a religious group (e.g., Hindu, Sikh, and Muslim). Smaller percentages of children described themselves as either 'Pakistani' (14\%), 'Nepalese' (4\%), 'Bengali' (9\%), or 'Sri Lankan' (6\%) and they also all described themselves by selecting a religious group (typically Muslim or Hindu).

Next, we identified the group memberships that were most important to the children. The words children had chosen were written on separate pieces of paper and placed in front of children. They were then instructed to consider all the words they had selected as self-descriptors and were asked 'Of those words that you chose, which is the most important one to you?' This word was then removed and children were asked 
to identify which of the remaining words was most important to them. This continued until all the self-descriptors had been rank ordered and the relative importance of each group category was determined. This procedure allowed us to identify the ethnic or religious minority status group the children most identified with. Forty-seven percent of the children rated 'Indian' as their most important ethnic minority status group, while $19 \%$ chose 'Sikh' and the remaining 34\% chose other categories including Muslim, Hindu, Pakistani, and Sri Lankan. Throughout the rest of the questionnaire, children's highest ranking minority status identity was considered to be the child's ethnic minority group membership. For the purposes of the remainder of this paper, this will be referred to as children's 'ethnic identity'.

It was then important to obtain a more precise measure of the strength of children's identification with their ethnic group. The measure of identity strength was adapted from Barrett's Strength of Identification Scale (SoIS: see Barrett, 2005). Children were presented with four questions relating to their identification with their ethnic group. These questions were 'How much are you [ethnic group]?' 'How proud are you about being [ethnic group]?' 'How important is it to you that you are [ethnic group]?' Children responded on a 4-point scale for these items $(1=$ not at all, $2=a$ little bit, $3=$ quite, $4=$ very). The different points on the response scale were illustrated pictorially with balloons of increasing size as in the response scale used for the peer acceptance measure. Finally, children were asked 'How do you feel about being [ethnic group]?' Children responded to this item on a 5-point Likert-type smiley face scale (see Cameron et al., 2006). Responses were scored 1-5 ( $1=$ very sad face, $2=$ sad face, $3=$ neutral, $4=$ bappy face, $5=$ very bappy face . The English identification measure was identical to the ethnic identification measure, but the items referred to 'English' rather than the child's ethnic group.

Analyses showed adequate internal reliability for ethnic identification (Cronbach's alpha $=.69$ ) and English identification (Cronbach's alpha $=.84$ ). Composite mean scores for ethnic and English identification were created. Higher scores in each measure indicated stronger identification.

\section{Preference for same-ethnic friendships}

We defined preference for same-ethnic friendships or friendship homophily as the percentage of same-ethnic minority status friends held by a child out of all their friends. In line with previous research (e.g., Feddes, Noack, \& Rutland, 2009; Titzmann \& Silbereisen, 2009), we asked children to name their five best friends. Children were asked to name five children they like to play with the most. Next they were presented with a list of words that they might use to describe their friends. These words described group memberships which included: (1) ethnic/national minority status groups ('Sri Lankan', 'Bengali', 'Hindu', 'Nepalese', 'Indian', 'Muslim', 'Pakistani', 'Asian', and 'Sikh'); (2) ethnic/national majority status groups ('white', 'English', 'British', and 'Christian') as well as some fillers ('girl' and 'boy') and an 'other' category. Children were then asked to identify the words they would use to describe each of their five friends. A friend described as belonging to any of the ethnic/national minority status groups was categorized as a same-ethnic friend. If a friend was not described as coming from any of these minority status groups they were categorized as a cross-ethnic friend. The variable, preference for same-ethnic friendships, was calculated by dividing the number of sameethnic friends by the total number of same-ethnic and cross-ethnic friends multiplied by 100. The resulting percentage was used as a measure of preference for same-ethnic friendships in our analysis. 
Table 2. Means and standard deviations of all variables and inter-correlations between variables at Time I

\begin{tabular}{|c|c|c|c|c|c|c|}
\hline Measure & Means (SD) & 1 & 2 & 3 & 4 & 5 \\
\hline $\begin{array}{l}\text { I. Perceived peer } \\
\text { acceptance }\end{array}$ & $\begin{array}{l}3.22 \\
(.53)\end{array}$ & - & $.16^{*}$ & .13 & -.01 & $-.17^{*}$ \\
\hline 2. Age (months) & $\begin{array}{l}95.80 \\
(18.10)\end{array}$ & & - & .09 & -.02 & -.08 \\
\hline 3. Ethnic identification & $\begin{array}{l}3.89 \\
(.53)\end{array}$ & & & - & $-.23^{*}$ & $.18^{*}$ \\
\hline 4. English identification & $\begin{array}{l}3.05 \\
(.93)\end{array}$ & & & & - & -.07 \\
\hline $\begin{array}{l}\text { 5. Preference for same- } \\
\text { ethnic friendships }\end{array}$ & $\begin{array}{l}44.21 \\
(32.74)\end{array}$ & & & & & - \\
\hline
\end{tabular}

Note. Perceived peer acceptance scores have a minimum of I and a maximum of 4 with higher scores indicating more peer acceptance among the children's peer group. Ethnic and English identification scores have a minimum of I and a maximum of 4.25 with a higher score showing more identification. Preference for same-ethnic friendships scores has a minimum of 0 and a maximum of 100 with a higher score showing more same-ethnic friendships.

${ }^{*} p<.05$.

\section{Procedure}

Children were interviewed individually by a researcher, with all measures contained within a booklet, to ensure good comprehension of all items across the age range. The measures were piloted and were pictorially based, in order to aid understanding particularly among young children. The order of each measure within the interview was fully counterbalanced. Children completed all measures at two time points, 6 months apart.

\section{Results}

Tables 2 and 3 provide the means and standard deviations for all variables at Time 1 and Time 2, respectively. Overall inter-correlations between variables at Time 1 and Time 2 are also shown in Tables 2 and 3, respectively. The analysis was first conducted with gender as a predictor. There were no main effects of gender and it did not interact with ethnic and English identity, therefore, it was excluded from subsequent analysis.

\section{Longitudinal analysis of the relationship between age, ethnic identity, English identity, and perceived peer acceptance}

First, we tested how much of the variance in perceived peer acceptance was attributable to differences between schools. This was necessary to ascertain whether we needed to use Hierarchical Linear Modeling (HLM; Raudenbush \& Bryk, 2002) for this analysis. Thus, we tested an unconditional means model for perceived peer acceptance at Time 2 . This model tested whether the means of Time 2 perceived peer acceptance differed across schools. Results showed that school-level estimates were non-significant $(B=.00006$, $p>.500$ ). The intra-class correlation suggested that less than $1 \%$ of the variance in perceived peer acceptance was attributable to differences across schools. These results demonstrate that the use of HLM was not necessary when examining the antecedents of children's perceived peer acceptance. 
Table 3. Means and standard deviations of all variables and inter-correlations between variables at Time 2

\begin{tabular}{lcccccc}
\hline Measure & Means (SD) & 1 & 2 & 3 & 4 & 5 \\
\hline I. Perceived peer & 3.12 & - & $.17^{*}$ & .14 & .11 & $-.20^{*}$ \\
acceptance & $.52)$ & & & & & \\
2. Age (months) & 95.80 & & - & .09 & .09 & -.08 \\
& $(18.10)$ & & & & -.10 & .04 \\
3. Ethnic identification & 3.92 & & & - & $-.17^{*}$ \\
& $(.55)$ & & & & - \\
4. English identification & 3.12 & & & & \\
5. Preference for same- & $(.93)$ & & & & & \\
ethnic friendships & $(32.37$ & & & & &
\end{tabular}

Note. Perceived peer acceptance scores have a minimum of I and a maximum of 4 with higher scores indicating more peer acceptance among the children's peer group. Ethnic and English identification scores have a minimum of $I$ and a maximum of 4.25 with a higher score showing more identification. Preference for same-ethnic friendships scores has a minimum of 0 and a maximum of 100 with a higher score showing more same-ethnic friendships.

${ }^{*} p<.05$.

Instead, OLS (ordinary least squares) cross-lagged regression analyses were used to investigate the causal relationships between children's ethnic identification, English identification, and perceived peer acceptance. These analyses are based upon the contention that the causality between variables $\mathrm{X}$ and $\mathrm{Y}$ can be inferred from longitudinal data by regressing $\mathrm{Y}$ at Time 2 on $\mathrm{X}$ at Time 1 while $\mathrm{Y}$ at Time 1 is also included in the regression model (Cohen, Cohen, West, \& Aiken, 2003). Residual variance (i.e., change) that is accounted for by variables from Time 1 can be assumed to be causal effects. We regressed peer acceptance at Time 2 on age, ethnic identification, English identification, and peer acceptance at Time 1. Peer acceptance at Time 1 was entered first and proved to be a significant predictor of peer acceptance at Time $2, \beta=.61, t=10.37, p<$ $.001, R^{2}=.37, F(1,185)=107.58, p<.001$. However, the addition of the main effects for age, ethnic identification, English identification, and the two-way interaction terms (Age X Ethnic identity; Age X English identity; English identity X Ethnic identity) did not significantly improve the model. As predicted, the three-way interaction between Age, Ethnic identity, and English identity at Time 1 was a significant predictor of peer acceptance at Time $2(\beta=.37, t=2.00, p<.05)$, and its addition significantly improved the model $\left(R^{2}=.402, F(8,185)=14.89, p<.001 ; R^{2}\right.$ Change $=.014, F(1,177)=4.01$, $p<.05)$.

This three-way interaction was examined by calculating simple slopes to identify the relationship between ethnic identification and English identification for younger and older children at 1 standard deviation above and below the mean age for the sample (Aiken \& West, 1991). The trend amongst the younger children was increasing ethnic identification at Time 1 that resulted in more peer acceptance at Time 2 if the children showed lower English identification but not if they showed higher English identification (see Figure 1); though the simple slopes for lower English identification $(t=.09, p=.93$ ) and higher English identification $(t=.06, p=.95)$ were both non-significant. In contrast, see Figure 2 , the pattern amongst the older children was increasing ethnic identification at Time 1 that resulted in more peer acceptance at Time 2 if the children showed higher 


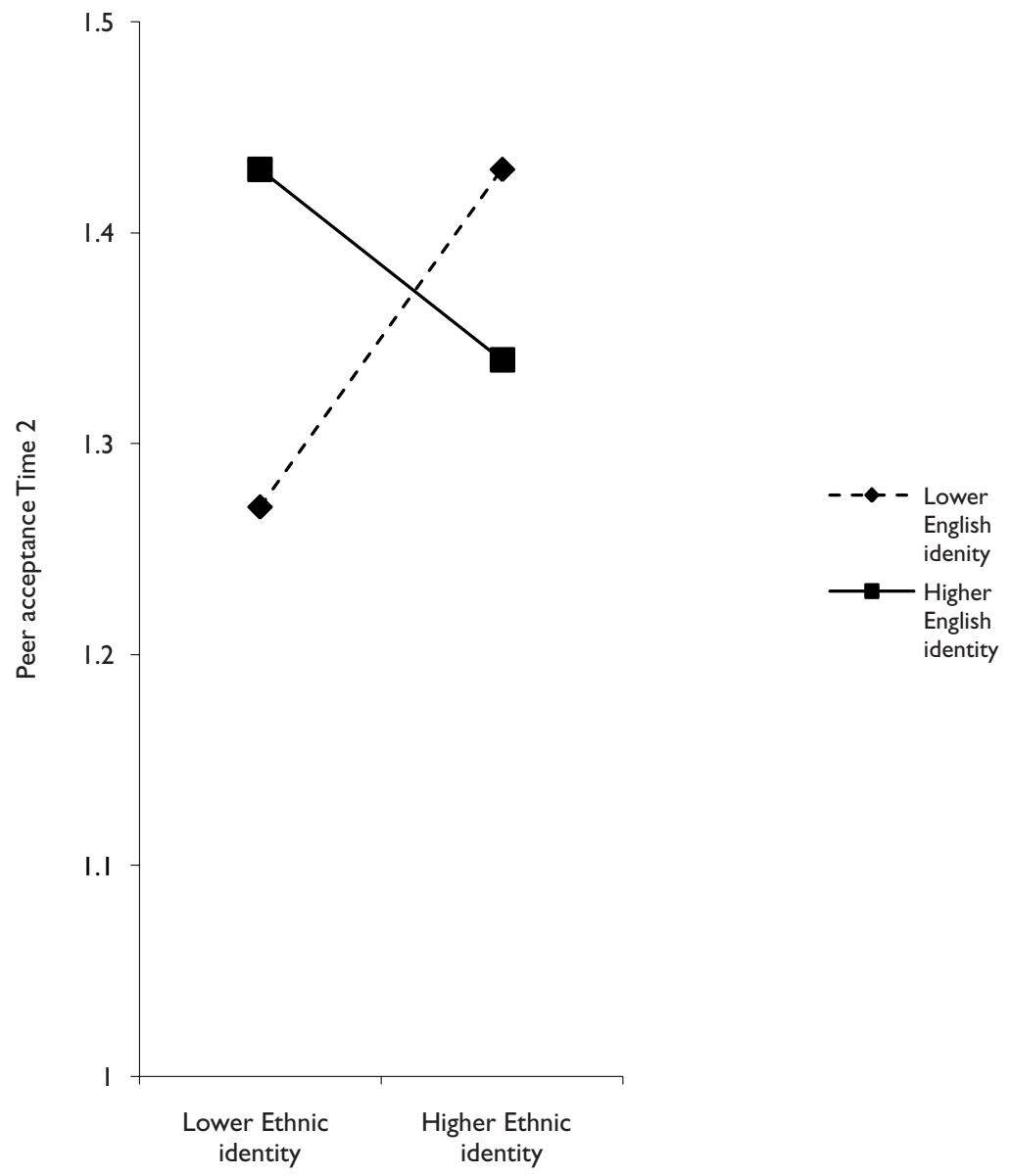

Figure I. Peer acceptance Time 2 as a function of English identification Time I and ethnic identification Time I amongst younger children.

English identification $(t=.10, p=.92)$ rather than lower English identification $(t=.11$, $p=.91)$. The simple slopes for higher English and lower English identification amongst both younger and older children were non-significant; however, importantly they were in opposite directions. Thus, younger children gained greater peer acceptance if they showed more ethnic identification combined with lower English identification. Older children, however, experienced more peer acceptance if they showed more ethnic identification together with higher English identification (i.e., a bicultural identity).

Next we tested whether the causal relationship was in the reverse direction (i.e., from peer acceptance to ethnic or English identification). Initially, we regressed ethnic identification at Time 2 on peer acceptance and age, together with their interaction term (i.e., Age X Peer acceptance) at Time 1, controlling for ethnic identification at Time 1 . Ethnic identification $(\beta=.39, t=5.72, p<.001)$ and peer acceptance $(\beta=.15, t=$ $2.09, p<.05)$ at Time 1 had significant effects on ethnic identification at Time $2\left(R^{2}=\right.$ $.18, F(1,179)=12.64, p<.001)$. The addition of age $(\beta=.02, t=.22, p=.83)$ and its interaction term $(\beta=-.04, t=-.60, p=.56)$, at Time 1 , did not significantly improve the regression model. Secondly, we regressed English identification at Time 2 on peer 


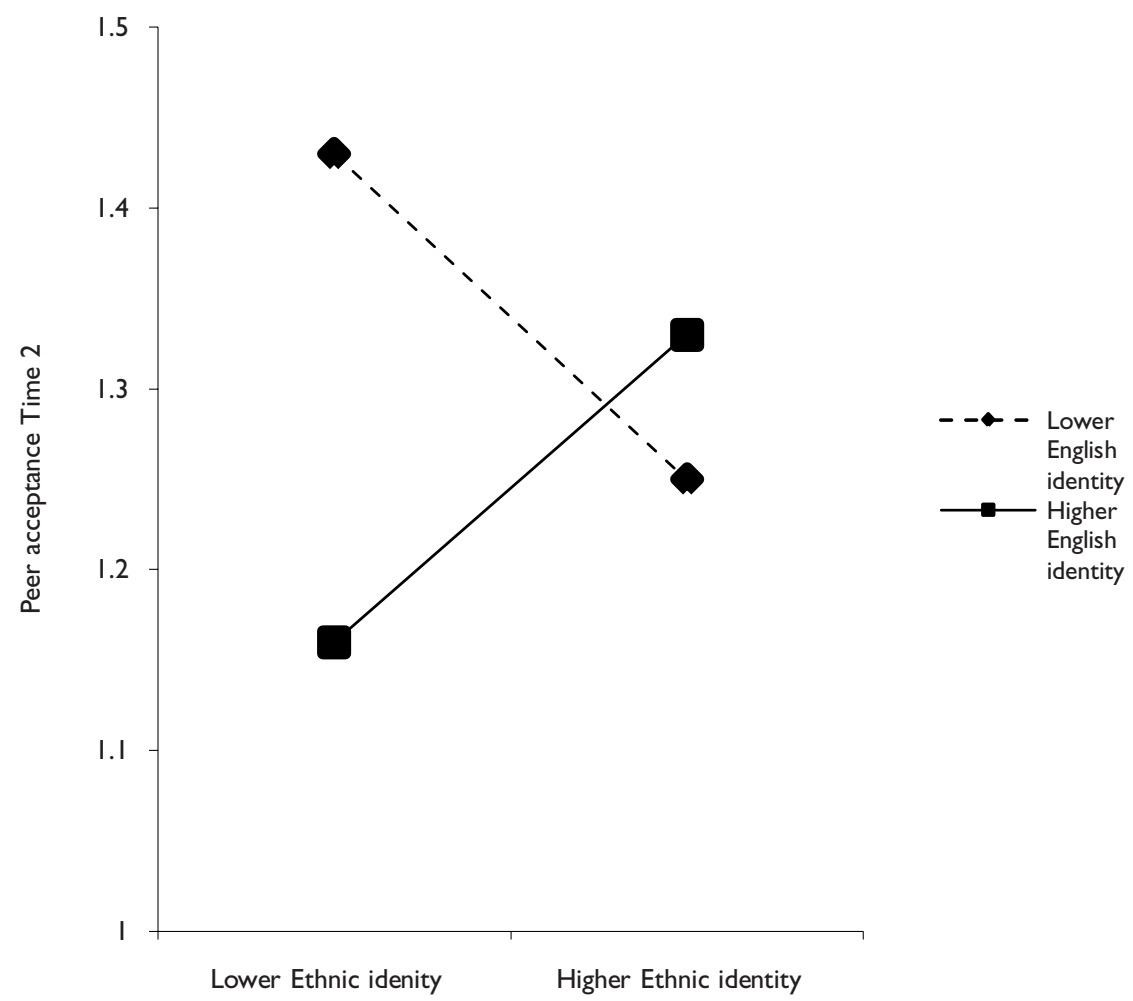

Figure 2. Peer acceptance Time 2 as a function of English identification Time I and ethnic identification Time lamongst older children.

acceptance and age, together with their interaction term (i.e., Age X Peer acceptance) at Time 1, controlling for English identification at Time 1. Only English identification at Time 1 had a significant effect on English identification at Time $2(\beta=.43, t=6.56, p<$ $\left..001, R^{2}=.18, F(1,195)=42.52, p<.001\right)$. The addition of peer acceptance $(\beta=.03$, $t=.51, p=.61)$, and age $(\beta=.10, t=1.57, p=.12)$ and their interaction term $(\beta=.05$, $t=.78, p=.43$ ), at Time 1 , did not significantly improve the regression model. Finally, we regressed the interaction between ethnic identification and English identification at Time 2 on peer acceptance and age, together with their interaction term (i.e., Age X Peer acceptance) at Time 1, controlling for the interaction between ethnic identification and English identification at Time 1 . This model proved non-significant $\left(R^{2}=.02, F(1\right.$, $177)=.89, p=.47)$. These analyses suggest there is also a causal relationship from perceived peer acceptance to ethnic identification, so children who experience more peer acceptance then show more ethnic identification. However, there was no causal relationship from peer acceptance to English identification.

\section{Longitudinal analysis of the relationship between ethnic and English identity, age,} ethnic diversity, and preference for same-ethnic friendships

Initially, we tested how much of the variance in preference for same-ethnic friendships was attributable to differences across schools. Thus, we tested an unconditional means model for same-ethnic friendships preference at Time 2 . This model tested whether the 
Table 4. Fixed effects and random effects of hierarchical linear model predicting same-ethnic friendship preference at Time 2 from ethnic and English identity, age, and school diversity

Coefficients

$(S E)$

\begin{tabular}{lr}
\hline Fixed effects & \\
Intercept & $-2.36(3.49)$ \\
Same-ethnic friendship preference Time I & $0.50(0.06)^{* * *}$ \\
Diversity & $0.40(0.2)^{\dagger}$ \\
Age & $-0.09(0.10)$ \\
English identification & $-2.35(2.14)$ \\
Ethnic identification & $-1.63(4.36)$ \\
English identification $\times$ Ethnic identification & $0.92(4.68)$ \\
English identification $\times$ Age & $0.10(0.12)$ \\
Ethnic identification $\times$ Age & $0.08(0.24)$ \\
English identification $\times$ Ethnic identification $\times$ Age & $-0.70(0.26)^{* *}$ \\
Random effects & \\
Level I & $543.00(23.30)$ \\
Level 2 & $84.34(9.18)^{* *}$ \\
\hline
\end{tabular}

Note. ${ }^{* *} p<.01 ;{ }^{* * *} p<.001 ;{ }^{\dagger} p<.10$. [Correction added on 22 December $201 \mathrm{I}$ after initial online publication on I June 20I I: 2 non-significant interaction co-efficients were omitted from the original version of the table and have been added to this version of the article.]

means of Time 2 preference for same-ethnic friendships differed across schools. Results showed that school-level estimates were marginally significant $(B=-9.69, p=.088)$. The intra-class correlation suggested that $32 \%$ of the variance in preference for same-ethnic friendships was attributable to differences across schools. Therefore, we proceeded with the analysis using HLM with restricted maximum likelihood estimation to examine the antecedents of preference for same-ethnic friendships.

To examine how ethnic and English identification and age were related to relative changes in preference for same-ethnic friendships, we ran a HLM model with Time 2 preference for same-ethnic friendships as the dependent variable. All continuous variables were grand-mean centred. Significant interactions were examined further using simple slopes analysis (Preacher, Curran, \& Bauer, 2006). In this model, we included Time 1 preference for same-ethnic friendships, age in months, and school diversity (on level 2) as covariates. Ethnic and English identification at Time 1 were entered as predictors. Additional two-way interaction terms (e.g., English identification $x$ Ethnic identification) and three-way interaction terms (e.g., English identification $\times$ Ethnic identification $x$ age) were included to test whether certain combinations of group identification at Time 1 would impact on preference for same-ethnic friendships at Time 2 and whether this would differ between younger and older children. The results are summarized in Table 4.

The results showed that Time 1 preference for same-ethnic friendships was a significant predictor of preference for same-ethnic friendships at Time 2 . This meant that Time 1 preference for same-ethnic friendships was associated with relative increases in preference for same-ethnic friendships over time. Further, as predicted, the interaction of English identity $\times$ ethnic identity $\times$ age was significant. To examine this interaction, simple slopes were calculated to indicate the relationship between ethnic identity and preference for same-ethnic friendships at 1 standard deviation above and below the mean 


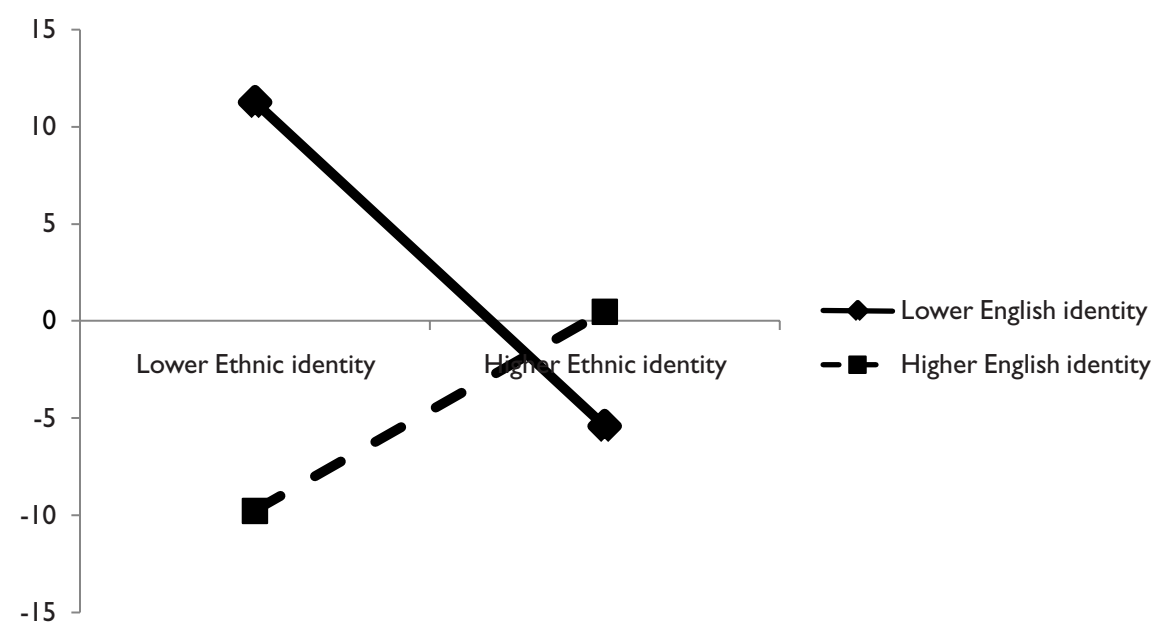

Figure 3. Preference for same-ethnic friendships at Time 2 for younger children as a function of ethnic and English identity.

age and the mean English identity for the sample (Aiken \& West, 1991). The simple slope between ethnic identity at Time 1 and preference for same-ethnic friendships at Time 2 was marginally significant for children who were both younger and higher English identifiers $(t=1.95, p=.052)$. None of the other simple slopes were significant.

This three-way interaction is presented in Figures 3 and 4. These findings signified that for younger ethnic minority status children higher ethnic identity is related to more preference for same-ethnic friendships, especially if they have a higher rather than lower English identity. In contrast, for older minority children, higher ethnic identity is related to more preference for same-ethnic friendships, only if they have lower rather than higher English identity. Older children showing higher English identification, with increasing ethnic identification demonstrated less preference for same-ethnic friendships. Overall, this three-way interaction indicates that with age, ethnic minority status children with higher bicultural identification (i.e., higher ethnic and English identity) are increasingly inclined to show less preference for same-ethnic friendships.

Finally, we tested whether the causal relationship was in the reverse direction (i.e., from preference for same-ethnic friendships to ethnic or English identification). We ran a HLM model with Time 2 Ethnic identity as the dependent variable, and Time 1 Ethnic identity, Time 1 English identity, age, and school diversity as predictors. This analysis only showed that Time 1 Ethnic identity was a significant predictor of ethnic identity at Time 2 . We also ran a HLM model with Time 2 English identity as the dependent variable, and Time 1 English identity, Time 1 Ethnic identity, age, and school diversity as predictors. Again only Time 1 English identity was a significant predictor of English identity at Time 2 . These analyses show that the causal relationship was not in the reverse direction.

\section{Discussion}

The findings of this longitudinal study show that peer relationships amongst ethnic minority status children reflect the social groups to which these children belong and the degree to which they identify with these groups. The study extends previous research on peer relations by demonstrating that bicultural identification is causally related to higher 


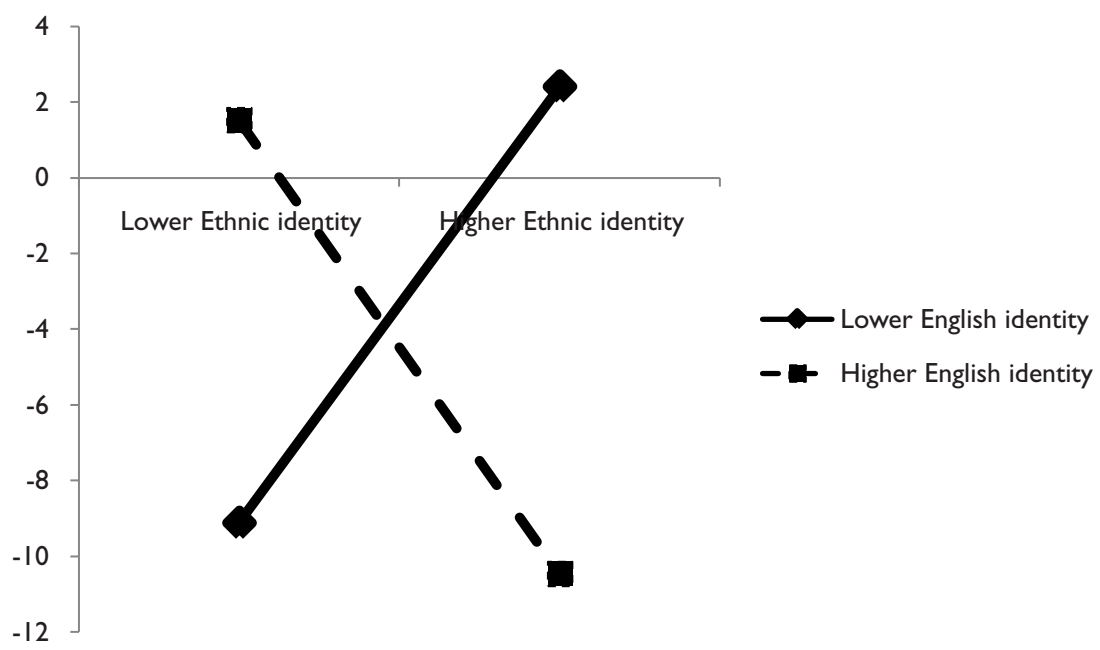

Figure 4. Preference for same-ethnic friendships at Time 2 for older children as a function of ethnic and English identity.

Note: Values of peer acceptance are derived from a regression equation in which peer acceptance is the dependent variable and age, English identification, and ethnic identification are independent variables. Effects of ethnic and English identification are represented by values $+1-1$ standard deviation from their mean. Values of preference for same-ethnic friendships are derived from a hierarchical linear model in which preference for same-ethnic friendships at Time 2 is the dependent variable and preference for same-ethnic friendships at Time I, school diversity, age, English and Ethnic identification are independent variables. Effects of age, ethnic, and English identity are represented by values $+I-I$ standard deviation from their mean.

perceived peer acceptance and less preference for same-ethnic friendships amongst ethnic minority status children. In line with our prediction, this relationship was only evident amongst the older children in our sample of 5- to 11-year-olds. This finding suggests that older children who adopted a bicultural identity (i.e., higher ethnic identity and English identity) were able to strategically 'flag' or perform their multiple identities to both their ethnic minority and ethnic majority peer groups. This meant they were able to gain acceptance amongst the maximum number of peers within their multicultural environment. These older bicultural children also showed less preference for same-ethnic friendships, which is in line with previous research showing that bicultural orientation is related to more positive inter-ethnic attitudes and cross-ethnic friendships (Binder et al., 2009; Cameron et al., 2006; Pfeifer et al., 2007).

These developmental trends were consistent with our prediction that only older children would be able to strategically adopt a bicultural identity because of their more advanced social-cognitive abilities. These abilities include the simultaneous consideration of multiple social categories or group memberships (i.e., ethnic and national) and the taking of other's perspective, understanding their thoughts and feelings during social interaction, and adopting group identities that will maximize peer acceptance. Developmental research shows that these social-cognitive abilities develop from approximately 7-8 years of age (Abrams et al., 2009; Barenboim, 1981; Bigler, 1995). These social-cognitive skills are particularly significant in the multicultural settings typically experienced by ethnic minority status children since they afford the opportunity to 
children to switch their cultural frame of reference and 'flag' different group identities and gain general peer acceptance. In addition, we contend that older ethnic minority status children skilled enough at adopting a bicultural identity should show more positive attitudes towards ethnic majority children, and this in part may explain why in the present study they showed less of a preference for same-ethnic friendships. This finding extends previous research in Germany using a smaller sample of ethnic minority status children (i.e., Turkish), which has shown that the adoption of a shared or common identity (i.e., classroom) is related to less preference for same-ethnic friendships (see Jugert et al., 2011).

Interestingly, the longitudinal analysis also revealed that, across all children, perceived peer acceptance affected subsequent levels of ethnic identification. It was found that children reporting reduced perceived peer acceptance subsequently reported lower levels of ethnic identification. This suggests ethnic minority status children respond to feelings of peer rejection by distancing themselves from their ethnic group. This strategy is perhaps unsurprising since in most schools included within this study ethnic minority status children were in the numerical minority. Therefore, one strategy to improve their chances of greater peer acceptance within the whole school could be to dissociate themselves from their ethnic group, which might make them more appealing to their ethnic majority status peers. Adopting a common or shared group identity (i.e., English identity) that they share with ethnic majority peers might be another strategy, but we found little evidence of this in the present longitudinal study.

Research shows that cross-ethnic friendships have many potential benefits, including more positive inter-group relations (Feddes et al., 2009) and higher levels of social competence (Eisenberg et al., 2009; Lease \& Blake, 2005). Therefore, it is disappointing that research shows, compared to same-ethnic friendships, cross-ethnic friendships are relatively uncommon and decline with age (e.g., Aboud, 2003; Smith \& Schneider, 2000). The findings of this longitudinal study suggest that, amongst ethnic minority status children, a preference for same-ethnic friendships could be overcome, and cross-ethnic friendship promoted, if interventions focused on facilitating a strong sense of both ethnic and national identity (i.e., bicultural identification). For example, interventions based upon extended contact (e.g., Cameron et al., 2006) are known to promote positive inter-group attitudes amongst ethnic majority status children, especially if they encourage children to focus on their bicultural or dual identities (i.e., subordinate and super-ordinate identities). The findings of the present study indicate such interventions might also be effective in encouraging more cross-ethnic friendships amongst ethnic minority status children.

\section{Limitations and future research}

Developmental trends in the influence of bicultural identification on children's perceived peer acceptance and preference for same-ethnic friendships were predicted based on previous research showing social-cognitive abilities (i.e., multiple classification skills and advanced social-perspective taking) develop during middle childhood (e.g., Barenboim, 1981; Baron-Cohen et al., 1999). We assumed that these important social-cognitive skills should impact on children's ability to strategically 'flag' or perform multiple identities and switch their cultural frame of reference. However, a limitation of the present study was that we did not investigate this social psychological process (i.e., the enactment of multiple group identities amongst peers) or measure the children's social-cognitive abilities. Future research should investigate this social psychological process more closely, and consider specific social-cognitive abilities that may be important in 
promoting bicultural identification, and subsequent changes in peer relationships. For example, future research could include measures of multiple classification ability (see Bigler \& Liben, 1992; Cameron, Rutland, \& Brown, 2007) and advanced socialperspective taking or Theory of Social Mind (see Abrams et al., 2009; Banerjee, 2000).

The present study would have also gained from including a measure of children's interethnic attitudes. We predicted based upon previous research that bicultural identification amongst the older children would be longitudinally related to less preference for sameethnic friendships. This was because research shows a bicultural orientation is related to more positive inter-group attitudes (Cameron et al., 2006; Pfeifer et al., 2007), and such attitudes are known to reduce children's preference for same-ethnic friendships (Jugert et al., 2011). The inclusion of an inter-group attitudes measure in the present study would have allowed us to examine whether the effect of bicultural identification on friendship choice was mediated by children's inter-ethnic attitudes.

High-quality cross-ethnic friendships are known to result in more positive intergroup outcomes (see Tropp \& Prenovost, 2008). In this study, preference for sameethnic friendships was assessed by asking children to state their five best friends and their ethnicity. Thus, our research focused on children's most high-quality friendships. Nonetheless, children are likely to have more than five friends, even though they may not be their best friends, and these friendships may also have positive consequences. Future research should include other measures of same-ethnic and cross-ethnic friendship, which can differentiate between levels of friendship quality. The peer-nomination technique, in which children are required to rate on a scale (i.e., 'best friend', 'good friend', 'OK friend', and 'OK but not really a friend') their level of friendship with every other child in their school class (see Aboud, Mendelson, \& Purdy, 2003; Jugert et al., 2011), would be a good alternative measure of friendship preference.

A friend, according to our measure of preference for same-ethnic friendship, described as belonging to any ethnic minority status group (e.g., Indian, Pakistani, and Sri Lankan) was categorized as a same-ethnic friend. Therefore, this measure meant our analysis could not consider separately friendships between children from different ethnic minority status groups (e.g., friendships between Indian-English and Pakistani-English children). This limitation was less severe in the context of the present study given the vast majority of the ethnic minority status children in our schools were Indian-English. This was reflected in the fact that approximately $79 \%$ of the children in our schools were Indian-English. However, future studies conducted in contexts with children from multiple ethnic minority status groups should also consider friendships between children from different ethnic minority status groups.

Another limitation of our research is that it focused on perceived peer acceptance only in the school context. Future research should examine the relationship between group identities and general peer relations in the many social contexts children form friendships. For example, sports teams, youth clubs, weekend religious or language schools, and after-school care. These settings may vary in their level of ethnic or cultural diversity and this might influence how different group identities affect peer relations. For instance, weekend Punjabi language schools are likely to be attended by south-Asian English children in our sample, therefore it is possible that children who identify strongly with their ethnic or religious group will feel more accepted and will be less lonely in this setting.

The present research demonstrates the importance of group identification in the formation of peer relations, but more recently researchers have called for more exacting measures and examination of group identities that take into consideration the 
multidimensional nature of these identities (Ashmore, Deaux, \& McLauhlin-Volpe, 2004; Ruble et al., 2004). Ruble and colleagues have identified a number of dimensions of group identity, namely, identity salience, centrality, knowledge, and public and private regard. Future research should examine how these components of group identity are important for peer relations.

To conclude, this longitudinal study has shown that bicultural identification amongst ethnic minority status children is related to higher perceived peer acceptance and less preference for same-ethnic friendships. The findings of this study extend previous peer relations research that has typically focused on how individual social deficits lead children to reject or be rejected by their peers, or the individual-group relationship only in terms of the classroom and not wider social groups (i.e., ethnic and national). This study demonstrates that peer relationships amongst ethnic minority status children living in multicultural settings also reflect the social groups to which children belong and the degree to which they identify with each group. Importantly, this conclusion was only true for older children within our sample. This result suggests that older children who adopted a bicultural identity (i.e., higher ethnic identity and English identity) were able to purposefully 'flag' their multiple group identities within their multicultural peer groups to obtain acceptance amongst the maximum number of peers and more crossethnic friendships. Future research should continue to use longitudinal designs in order to have more certainty when drawing causal relationships between group identities and peer relations. This research would benefit from the inclusion of additional socialcognitive, inter-group attitude, peer relations measures, and a more nuanced conception of group identity. Peer relations are essential for the psychological development of ethnic minority status children growing up in multicultural communities, and this study helps us understand how group identities are an important factor in this process.

\section{References}

Aboud, F. E. (2003). The formation of ingroup favoritism and outgroup prejudice in young children: Are they distinct attitudes? Developmental Psychology, 39, 48-60. doi:10.1037/00121649.39.1.48

Aboud, F. E., Mendelson, M. J., \& Purdy, K. T. (2003). Cross-race peer relations and friendship quality. International Journal of Behavioral Development, 27, 165-173. doi:10.1080/01650250244000164

Abrams, D., Hogg, M., \& Marques, J. M. (2005). A social psychological framework for understanding social inclusion and social exclusion. In D. Abrams, M. Hogg, \& J. M. Marques (Eds.), The social psychology of inclusion and exclusion. New York: Psychology Press.

Abrams, D., \& Rutland, A. (2008). The development of subjective group dynamics. In S. Levy \& M. Killen (Eds.), Intergroup attitudes and relations in childbood through adulthood. Oxford, UK: Oxford University Press.

Abrams, D., Rutland, A., Pelletier, J., \& Ferrell, J. (2009). Children's group nous: Understanding and applying peer exclusion within and between groups. Child Development, 80, 224-243. doi:10.1111/j.1467-8624.2008.01256.x

Aiken, L. S., \& West, S. G. (1991). Multiple regression: Testing and interpreting interactions. Newbury Park, CA: Sage.

Ambady, N., Shih, M., Kim, A., \& Pittinsky, T. (2001). Stereotype suceptability in children: Effects of identity activation on quantitative performance. Psychological Science, 12, 385390. doi:10.1111/1467-9280.00371

Ashmore, R. D., Deaux K., \& McLaughlin-Volpe, T. (2004). An organizing framework for collective identity: Articulation and significance of multidimensionality. Psychological Bulletin, 130, 80-114. 
Banerjee, R. (2000). The development of an understanding of modesty. British Journal of Developmental Psychology, 18(4), 499-517.

Barenboim, C. (1981). The development of person perception in childhood and adolescence: From behavioral comparisons to psychological constructs to psychological comparisons. Child Development, 52, 129-144. doi:10.2307/1129222

Baron-Cohen, S., O'Riordan, M., Stone, V., Jones, R., \& Plaisted, K. (1999). Recognition of faux pas by normally developing children and children with asperger syndrome or high-functioning autism. Journal of Autism \& Developmental Disorders, 29(5), 407-418. doi:10.1023/A:1023035012436

Barrett, M. (2005). Children's understanding of, and feelings about, countries and national groups. In M.Barrett \& E.Buchana-Barrow (Eds.), Children's understanding of society (pp. 251-286). New York: Psychology Press.

Benet-Martinez, V., \& Haritatos, J. (2005). Bicultural Identity Integration (BII): Components and psychosocial antecendents. Journal of Personality, 73(4), 1015-1050. doi:10.1111/j.14676494.2005.00337.x

Bennett, M., \& Sani, F. (Eds.). (2004). The development of the social self. Philidelphia: Psychology Press.

Berlin, L. J., Cassidy, J., \& Belsky, J. (1995). Loneliness in young children and infant-mother attachment: A longitudinal study. Merrill-Palmer Quarterly, 41, 91-103.

Berry, J. W., Phinney, J. S., Sam, D. L., \& Vedder, P. (2006). Immigrant youth: Acculturation, identity, and adaptation. Applied Psychology: An International Review, 55(3), 303332. doi:10.1111/j.1464-0597.2006.00256.x

Bigler, R. S. (1995). The role of classification skill in moderating environmental influences on children's gender stereotyping: A study of the functional use of gender in the classroom. Child Development, 66, 1072-1087. doi:10.2307/1131799

Bigler, R. S., \& Liben, L. (1992). Cognitive mechanisms in children's gender stereotyping: Theoretical and educational implications of a cognitive-based intervention. Child Development, 63, 1351-1363. doi: $10.2307 / 1131561$

Binder, J., Zagefka, H., Brown, R., Funke, F., Kessler, T., \& Mummendey, A. (2009). Does contact reduce prejudice or does prejudice reduce contact? A longitudinal test of the contact hypothesis among majority and minority groups in three European countries. Journal of Personality and Social Psychology, 96, 336-383. doi:10.1037/a0013470

Boivin, M., Hymel, S., \& Bukowski, W. M. (1995). The roles of social withdrawal, peer rejection, and victimization by peers in predicting loneliness and depressed mood in children. Development and Psychopathology, 7, 765-786. doi:10.1017/\$0954579400006830

Brown, R., \& Hewstone, M. (2005). An integrative theory of intergroup contact. Advances in Experimental Social Psychology, 37, 255-343.

Calzada, E. J., Brotman, L. M., Huang, K., Bat-Chava, Y., \& Kingston, S. (2009). Parent cultural adaptation and child functioning in culturally diverse, urban families of preschoolers. Journal of Applied Developmental Psychology, 30, 515-524. doi:10.1016/j.appdev.2008.12.033

Cameron, L., Rutland, A., \& Brown, R. J. (2007). Promoting children's positive intergroup attitudes towards stigmatized groups: Extended contact and multiple classification skills training. International Journal of Behavioral Development, 31(5), 454-466. doi: $10.1177 / 0165025407081474$

Cameron, L., Rutland, A., Brown, R. J., \& Douch, R. (2006). Changing children's intergroup attitudes toward refugees: Testing different models of extended contact. Child Development, 77(5), 1208-1219. doi:10.1111/j.1467-8624.2006.00929.x

Cassidy, J., \& Asher, S. R. (1992). Loneliness and peer relations in young children. Child Development, 63(2), 350-365. doi:10.2307/1131484

Chang, L. (2004). The role of classroom norms in contextualizing the relations of children's social behaviors to peer acceptance. Developmental Psychology, 40(5), 691-702. doi:10.1037/00121649.40.5.691 
Cohen, J., Cohen, P., West, S. G., \& Aiken, L. S. (2003). Applied multiple regression/correlation analysis for the behavioural sciences (3rd ed.). London: Erlbaum.

Coplan, R. J., Closson, L. M., \& Arbeau, K. A. (2007). Gender differences in the behavioral associates of loneliness and social dissatisfaction in kindergarten. Journal of Child Psychology and Psychiatry, 48, 988-995. doi:10.1111/j.1469-7610.2007.01804.x

Eisenberg, N., Sallquist, J., French, D. C., Purwono, U., Suryanti, T. A., \& Pidada, S. (2009). The relations of majority-minority group status and having an other-religion friend to Indonesian youths' socioemotional functioning. Developmental Psychology, 45, 248-259. doi:10.1037/a0014028

Feddes, A. R., Noack, P., \& Rutland, A. (2009). Direct and extended friendship effects on minority and majority children's interethnic attitudes: A longitudinal study. Child Development, 80, 337-390. doi:10.1111/j.1467-8624.2009.01266.x

FitzRoy, S., \& Rutland, A. (2010). Learning to control ethnic intergroup bias in childhood. European Journal of Social Psychology, 40, 679-693. doi:10.1002/ejsp.746

Gaertner, S. L., Dovidio, J. F., Guerra, R., Rebelo, M., Monteiro, M. B., Riek, B. M., \& Houlette, M. A. (2008). The common in-group identity model: Applications to children and adults. In S. R. Levy \& M. Killen (Eds.), Intergroup attitudes and relations in childhood through adulthood (pp. 204-219). Oxford, U.K.: Oxford University Press.

Hay, D. F., Payne, A., \& Chadwick, A. (2004). Peer relations in childhood. Journal of Child Psychology \& Psychiatry, 45, 84-108.

Hymel, S., Vaillancourt, T., McDougall, P., \& Renshaw, P. D. (2002). Peer acceptance and rejection in childhood. In P. K. Smith \& C. H. Hart (Eds.), Blackwell handbook of childbood social development (pp. 265-284). Oxford: Blackwell Publishing.

Jugert, P., Noack, P., \& Rutland, A. (2011). Friendship preferences among German and Turkish preadolescents. Child Development, 82, 812-829. doi:10.1111/j.1467-8624.2010.01528.x

Juvonen, J., Gross, E. F., Williams, K. D., Forgas, J. P., \& von Hippel, W. (2005). The rejected and the bullied: Lessons about social misfits from developmental psychology. In K. D. Williams \& J. P. Forgas (Eds.), The social outcast: Ostracism, social exclusion, rejection, and bullying (pp. 155-170). New York: Psychology Press.

Killen, M., \& Rutland, A. (2011). Children and Social Exclusion: Morality, Prejudice and Group Identity. Oxford: Wiley-Blackwell.

Knight, G. P., Virdin, L., \& Roosa, M. (1994). Socialization and family correlates of mental health outcomes among Hispanic and Anglo-American families. Child Development, 65, 212-224. doi: $10.2307 / 1131376$

LaFromboise, T., Coleman, H. L. K., \& Gerton, J. (1993). Psychological impact of biculturalism: Evidence and Theory. Psychological Bulletin, 114(3), 395-412. doi:10.1037/00332909.114.3.395

Lease, A. M., \& Blake, J. J. (2005). A comparison of majority-race children with and without a minority-race friend. Social Development, 14, 20-41. doi:10.1111/j.1467-9507.2005.00289.x

Livesley, W. J., \& Bromley, D. B. (1973). Person Perception in childbood and adolescence. New York: Wiley.

Nesdale, D. (2008). Peer group rejection and children's intergroup prejudice. In S. R. Levy \& M. Killen (Eds.), Intergroup attitudes and relations in childhood through adulthood (pp. 3246). Oxford, U.K.: Oxford University Press.

Pfeifer, J. H., Ruble, D. N., Bachman, M. A., Alvarez, J. M., Cameron, J. A., \& Fuligni, A. J. (2007). Social identities and intergroup bias in immigrant and nonimmigrant children. Developmental Psychology, 43, 496-507. doi:10.1037/0012-1649.43.2.496

Phinney, J. S., Cantu, C. L., \& Kurtz, D. A. (1997). Ethnic and American identity as predictors of selfesteem among American, Latino, and white adolescents. Journal of Youth and Adolescence, 26, 165-185. doi:10.1023/A:1024500514834

Phinney, J. S., Horenezyk, G., Liebkind, K., \& Vedder, P. (2001). Ethnic Identity, Immigration, and Well-Being: An Interactional Perspective. Journal of Social Issues, 57(3), 493. doi: $10.1111 / 0022-4537.00225$ 
Phinney, J. S., Jacoby, B., \& Silva, C. (2007). Positive intergroup attitudes: The role of ethnic identity. International Journal of Behavioral Development, 31(5), 478-490. doi: $10.1177 / 0165025407081466$

Preacher, K. J., Curran, P. J., \& Bauer, D. J. (2006). Computational tools for probing interaction effects in mulitple linear regression, multilevel modeling, and latent curve analysis. Journal of Educational and Behavioral Statistics, 31, 437-448. doi:10.1037/1082-989X.11.2.142; 10.1037/1082-989X.11.2.142.supp (Supplemental)

Raudenbush, S. W., \& Bryk, A. S. (2002). Hierarchical linear models: Applications and data analysis methods. Newbury Park: Sage.

Rubin, K. H., Bukowski, W., \& Parker, J. G. (2006). Peers, relationships, and interactions. In W. Damon \& R. Lerner (Eds.), Handbook of child psychology. New York: Wiley Publishers.

Rutland, A., Killen, M., \& Abrams, D. (2010). A new social-cognitive developmental perspective on prejudice: The interplay between morality and group identity. Perspectives on Psychological Science, 5, 279-291. doi:10.1177/1745691610369468

Sani, F., \& Bennett, M. (2001). Contextual variability in young children's gender ingroup stereotype. Social Development, 10, 221-229. doi:10.1111/1467-9507.00160

Smith, A., \& Schneider, B. (2000). The interethnic friendship of adolescent students: A Canadian study. International Journal of Intercultural Relations, 24, 247-258. doi:10.1016/S01471767(99)00034-6

Titzmann, P. F., \& Silbereisen, R. K. (2009). Friendship homophily among ethnic German immigrants: A longitudinal comparison between recent and more experienced immigrant adolescents. Journal of Family Psychology, 23, 301-310. doi:10.1037/a0015493

Tropp, L. R., \& Prenovost, M. A. (2008). The role of intergroup contact in predicting children's inter-ethnic attitudes: Evidence from meta-analytic and field studies. In S. Levy \& M. Killen (Eds.), Intergroup attitudes and relations in childhood through adulthood. Oxford, U.K.: Oxford University Press.

Verkuyten, M., \& Pouliasi, K. (2002). Biculturalism among older children: Cultural frame switching, attributions, self-identification, and attitudes. Journal of Cross-Cultural Psychology, 33, 596609. doi:10.1177/0022022102238271

Wang, Q., Shao, Y., \& Li, Y. J. (2010). 'My way or mom's way?' The bilingual and bicultural self in Hong Kong Chinese children and adolescents. Child Development, 81, 555-567. doi:10.1111/j.1467-8624.2009.01415.x

Woods, S., Done, J., \& Kalsi, H. (2009). Peer victimisation and internalising difficulties: The moderating role of friendship quality. Journal of Adolescence, 32, 293-308. doi:10.1016/j.adolescence.2008.03.005 